\title{
Mineralocorticoid receptor antagonist use after hospitalization of patients with heart failure and post-discharge outcomes: a single-center retrospective cohort study
}

\author{
Matthew S. Durstenfeld ${ }^{1}$, Stuart D. Katz ${ }^{2}$, Hannah Park ${ }^{3}$ and Saul Blecker ${ }^{2,3^{*}}$ (D)
}

\begin{abstract}
Background: Mineralocorticoid receptor antagonists (MRA) are an underutilized therapy for heart failure with a reduced ejection fraction (HFrEF), but the current impact of hospitalization on MRA use is not well characterized. The objective of this study was to describe contemporary MRA prescription for heart failure patients before and after the full scope of hospitalizations and the association between MRA discharge prescription and post-hospitalization outcomes.

Methods: We conducted a retrospective cohort study at an academic hospital system in 2013-2016. Among 1500 included hospitalizations of 1009 unique patients with HFrEF and without MRA contraindication, the mean age was $71.9 \pm$ 13.6 years and 443 (29.5\%) were female. We compared MRA prescription before and after hospitalizations with McNemar's test and between patients with principal and secondary diagnoses of HFrEF with the chi-square test, and association of MRA discharge prescription with 30-day and 180-day mortality and readmissions using generalized estimating equations

Results: MRA prescriptions increased from 303 (20.2\%) to 375 (25.0\%) at discharge ( $+4.8 \%, p<0.0001)$. More patients with principal diagnosis of HFrEF compared to those hospitalized for other reasons received MRA (34.9\% versus 21.3\%, $p<0.0001)$ and had them initiated $(21.8 \%$ versus $9.7 \%, p<0.0001)$. MRA prescription at discharge was not associated with mortality or readmission at 30 and 180 days, and there was no interaction with principal/secondary diagnosis.

Conclusions: Among hospitalized HFrEF patients, 75\% did not receive MRA before or after hospitalization, and nearly $90 \%$ of eligible patients did not have MRA initiated. As we found no signal for short-term harm after discharge, hospitalization may represent an opportunity to initiate guideline-directed heart failure therapy.
\end{abstract}

Keywords: Mineralocorticoid, Aldosterone, Heart Failure, Hospitalization

\section{Background}

Heart failure is a major cause of hospital admission, particularly among older patients. By 2030, over 8 million Americans are projected to have heart failure with an estimated cost of $\$ 69.8$ billion, with up to $80 \%$ of costs related to hospitalization [1]. High-quality trials have demonstrated that mineralocorticoid receptor antagonists (MRA) including spironolactone and eplerenone reduce mortality and readmissions among patients with heart failure with a reduced

\footnotetext{
* Correspondence: saul.blecker@nyumc.org

2Department of Medicine, New York University School of Medicine, 227 East 30th Street, New York, NY 10016, USA

${ }^{3}$ Department of Population Health, New York University School of Medicine, 227 East 30th Street, New York, NY 10016, USA

Full list of author information is available at the end of the article
}

ejection fraction (HFrEF) compared to placebo [2-5]. In a meta-analysis, HFrEF patients treated with MRA had reduced mortality (Odds Ratio (OR) 0.77, 95\% Confidence Interval (CI) 0.61-0.89) and reduced cardiovascular-specific hospitalization (OR 0.66, 95\% CI 0.51-0.85) [6]. Based on the evidence, the American College of Cardiology/American Heart Association Guideline for the Management of Heart Failure includes a strong recommendation (Class IA) to use MRA in patients with left ventricular ejection fraction (LVEF) of 35\% or less with New York Heart Association (NYHA) Class II-IV symptoms, estimated glomerular filtration rate $(\mathrm{eGFR})>30 \mathrm{ml} / \mathrm{min} / 1.73 \mathrm{~m}^{2}$, and serum potassium $<5.0 \mathrm{mEq} / \mathrm{L}[7,8]$.

(c) The Author(s). 2019 Open Access This article is distributed under the terms of the Creative Commons Attribution 4.0 International License (http://creativecommons.org/licenses/by/4.0/), which permits unrestricted use, distribution, and reproduction in any medium, provided you give appropriate credit to the original author(s) and the source, provide a link to the Creative Commons license, and indicate if changes were made. The Creative Commons Public Domain Dedication waiver (http://creativecommons.org/publicdomain/zero/1.0/) applies to the data made available in this article, unless otherwise stated. 
Despite a strong level of evidence and inclusion in guidelines, MRA remain underutilized. MRA prescription rates for HFrEF patients range from $15-29 \%$ in the ambulatory setting [9-12] to $27-33 \%$ after heart failure hospitalization [11, 13-15]. Only $36 \%$ of veterans hospitalized with $\mathrm{HFrEF}$ in 2003-2009 who were "ideal candidates" for MRA received them, with significant practice variation and decrease in use over time to $31 \%$ by 2009 [16]. In a national sample of over 200,000 patients with HFrEF from 2009 to 2012, only $9 \%$ filled prescriptions for MRA [17].

Hospitalization may present an opportunity to increase adherence to guideline directed therapy, especially for patients with a secondary diagnosis of HFrEF. Data from almost a decade ago suggest that hospitalization, including heart-failure specific hospitalization, does not impact prescription of MRA [17]. Furthermore, patients with heart failure hospitalized for other reasons are less likely to receive guideline-directed medical therapy including MRA than patients hospitalized for heart failure [18]. Accordingly, the current study was conducted to describe contemporary MRA prescription for heart failure patients before and after the full scope of hospitalizations and the association between MRA discharge prescription and outcomes.

\section{Methods}

We performed a retrospective cohort study of adults hospitalized within an academic tertiary-care hospital system from January 2013 to May 2016 with a principal or secondary discharge diagnosis of heart failure as defined by standard ICD-9CM and ICD-10 codes. Prior research suggests that the specificity of principal diagnosis of heart failure for acute decompensated heart failure is $>95 \%$ with $>87 \%$ positive predictive value for acute decompensated heart failure [19], and hospitalizations of patients hospitalized for other issues were coded with heart failure as a secondary diagnosis. We included patients with LVEF $\leq 35 \%$, eGFR $>30 \mathrm{ml} / \mathrm{min} / 1.73 \mathrm{~m}^{2}$, serum potassium $<5.0 \mathrm{mEq} / \mathrm{L}$, and systolic blood pressure (SBP) $\geq 100 \mathrm{mmHg}$ prior to discharge [7]. We excluded patients who died during the index admission, were discharged to hospice, or were pregnant. We identified our cohort using clinical data from the electronic health record (Epic Systems Corporation, Verona, Wisconsin). We extracted demographic, clinical, and billing information including MRA prescription before admission and at discharge and validated the data extraction with manual chart review of a subset of the cohort. To identify readmissions, patient data were linked to the New York State Planning and Research Cooperative System data registry, which includes all acute-care hospitalizations within New York State excluding federal hospitals such as Veterans Affairs hospitals [20]. To identify mortality events, patient data were linked to the New York State Vital Statistics registry. This study was approved by the New York University School of Medicine Institutional Review Board, and a waiver of consent was granted.
Our primary outcome was MRA prescription at the time of hospital discharge. We compared MRA prescription before and after hospitalization including change in MRA prescription status, MRA discontinuation, MRA prescription at discharge, and new MRA initiation with pre-specified principal and secondary diagnosis subgroups. Then we examined the association between MRA prescription at discharge and 30-day and 180-day outcomes of all-cause readmissions, heart-failure readmissions, hyperkalemia readmissions, and mortality. We defined heart failure readmissions by ICD-9-CM or ICD-10 codes for heart failure in the primary position and hyperkalemia-specific readmission by ICD-9-CM or ICD-10 hyperkalemia code in any position.

Patient demographic variables included age, sex, and race/ethnicity. Clinical data included LVEF, as measured during the hospitalization or within the preceding three months and extracted from echocardiogram reports as a structured data element, and first available systolic blood pressure from the visit. Laboratory values including sodium, potassium, and creatinine were collected at admission and the last values prior to discharge. Estimated glomerular filtration rates (eGFR) were calculated using the CKD-EPI formula [21]. Comorbid conditions including hypertension, atrial fibrillation/flutter, diabetes mellitus, chronic kidney disease, malignancy, cerebrovascular disease, peripheral vascular disease, acute myocardial infarction, chronic obstructive pulmonary disease, dementia, and cirrhosis were assigned based on discharge ICD-9-CM and ICD-10 codes. We recorded preadmission and discharge medication prescriptions for the angiotensin converting enzyme (ACE)-inhibitors, angiotensin receptor blockers (ARB), beta-blockers, loop diuretics, and mineralocorticoid receptor antagonists.

\section{Statistical Analysis}

We used McNemar's test to compare MRA prescription before and after hospitalization in the entire cohort and with principal and secondary diagnosis subgroups. We used the chi-square test to compare discharge MRA prescriptions and new MRA initiation between principal and secondary diagnosis subgroups. To compare covariates among patients who did or did not receive MRA at discharge, we used the chi-square test for categorical variables and the t-test for continuous variables. Tests were evaluated at a two-sided significance level of $p<0.05$.

We reported unadjusted readmissions and mortality at 30 days and 180 days for patients who were prescribed MRA versus those not prescribed MRA, with readmissions stratified into all-cause, heart failure principal diagnosis, and hyperkalemia-related. To compare adjusted mortality and readmissions at 30 days and 180 days for patients prescribed MRA therapy versus those not prescribed MRA, we developed models using generalized-estimating equations (GEE). The primary independent variable was MRA prescription 
at discharge. Readmissions were stratified into all-cause, heart failure principal diagnosis, and hyperkalemia-related. Because our study was observational rather than a randomized clinical trial, we adjusted the odds ratios based on factors that known to be associated with worse prognosis in heart failure. Our adjusted GEE models account for repeat hospitalizations of the same patient with adjustment for demographics, comorbid conditions, admission systolic blood pressure, admission sodium, discharge eGFR, and LVEF. We considered p-values $<0.05$ to be significant a priori and reported unadjusted and adjusted odds ratios with $95 \%$ confidence intervals.

To determine if there was a difference in outcomes with MRA prescriptions between patients with a principal and secondary diagnosis, we developed a second set of GEEs with an interaction term for discharge prescription and an indicator for heart failure diagnosis position as principal versus secondary. We adjusted these models for the same variables as the prior models. We considered $\mathrm{p}$-values $<0.10$ to be significant for interaction a priori. Analyses were performed with STATA version SE 13.1 (StataCorp, College Station, TX).

\section{Results}

Study population was represented by 1009 unique patients affected by heart failure, with 1500 hospitalizations (Table 1). The mean age of included patients was $71.9 \pm 13.6$ years and $443(29.5 \%)$ were female (Table 1 ). Of these, $227(15.1 \%)$ identified as black and $97(6.5 \%)$ as Hispanic. Comorbid conditions were prevalent among our cohort: $76.7 \%$ had hypertension, $52.8 \%$ had atrial fibrillation, 41.1\% had diabetes, and 34.1\% had chronic kidney disease stages 1-3 (Table 1). Most patients were prescribed ACE inhibitors or ARB (59\% before, $65 \%$ after), beta blockers (73\% before, $78 \%$ after), and loop diuretics (58\% before, $68 \%$ after) (Table 1). There were significant differences in comorbidities among patients with a principal as compared to secondary diagnosis of heart failure, including higher rates of diabetes and chronic kidney disease and lower rates of myocardial infarction (Table 1).

Among 1500 hospitalizations, 303 patients (20.2\%) were prescribed MRA prior to hospitalization, and 375 patients (25.0\%) were prescribed MRA at discharge for a net increase of 72 patients $(+4.8 \%)$ prescribed MRA post-hospitalization $(p<0.0001$, Figure 1). Of the 303 patients prescribed MRA prior to hospitalization, 223 patients $(73.6 \%)$ continued and 80 patients $(26.4 \%)$ discontinued MRA at discharge. Out of 1197 patients not prescribed MRA prior to hospitalization, 152 patients $(12.7 \%)$ had MRA initiated and 1045 patients (87.3\%) were never prescribed MRA. Patients who received MRA at discharge were younger $(69.7 \pm 13.6$ versus $72.6 \pm$ 13.2 years old, $p=0.0003)$, had lower $\operatorname{LVEF}(23.9 \pm 7.0$ versus $27.3 \pm 7.1 \%, p<0.0001)$, had lower admission systolic blood pressures $(128.6 \pm 23.3$ versus $131.4 \pm 23.9 \mathrm{mmHg}, \quad p=$
0.0475), and were more likely to receive other guideline-directed medical therapies at discharge including ACE inhibitors or ARBs and beta blockers (Appendix).

Among 407 patients with a principal diagnosis of heart failure, $109(26.8 \%)$ were prescribed MRA prior to hospitalization, and $142(34.9 \%)$ were prescribed MRA at discharge for a net increase of 33 patients $(+8.1 \%, p=$ 0.0008). Among 1093 patients with a secondary diagnosis of heart failure, 194 patients (17.7\%) were prescribed MRA before hospitalization and 233 patients (21.3\%) were prescribed MRA after hospitalization for a net increase of $3.6 \%$ $(p=0.0008)$. Patients hospitalized with a principal diagnosis of heart failure were more likely to receive MRA at discharge than patients hospitalized with a secondary diagnosis: $34.9 \%$ versus $21.3 \%(p<0.0001)$. Likewise, patients with a principal diagnosis were also more likely to have MRA initiated: $21.8 \%$ versus $9.7 \%(p<0.0001)$. There were no differences in MRA discontinuation among patients with a principal versus secondary diagnosis of heart failure: $29.4 \%$ versus $24.7 \%(p=0.38)$.

Among 1500 hospitalizations, post-discharge outcomes were available for 1463 . The 30-day mortality rate among patients prescribed MRA at discharge was $3.0 \%$ compared to $2.5 \%$ for patients not prescribed MRA at discharge (OR $1.23,95 \%$ CI $0.61-2.51$ ). The 180-day mortality rate was 9.3 and $10.2 \%$ among patients prescribed MRA and not prescribed MRA at discharge, respectively (OR 0.90, 95\% CI $0.60-1.35$ ). The 30 -day all cause readmission rate was $22.2 \%$ for patients prescribed MRA and $21.6 \%$ for patients not prescribed MRA at discharge (OR 1.04, 95\% CI 0.78-1.38). The 180 -day all-cause readmission rate was $43.6 \%$ for patients prescribed MRA versus $46.4 \%$ for patients not prescribed MRA at discharge (OR 0.89, 95\% CI 0.70-1.13). There were more 30-day heart failure specific readmissions among patients prescribed MRA than patients not prescribed MRA at discharge (7.4\% versus $4.5 \%$, OR $1.71,95 \%$ CI $1.05-2.78$ ). Similarly, patients prescribed MRA at discharge had more 180-day heart failure specific readmissions compared to those not prescribed MRA (20.8\% versus $15.5 \%$, OR 1.44 , 95\% CI 1.06-1.94). There were no differences in 30-day or 180-day hyperkalemia readmissions (Table 2).

There were no associations between MRA prescription at discharge and short-term mortality and readmissions after adjusting for demographics, comorbid conditions, systolic blood pressure at admission, discharge estimated glomerular filtration rate, ejection fraction, and repeat hospitalizations of the same patient (Table 2). The associations between MRA prescription and heart failure specific readmissions at 30 days and 180 days were no longer statistically significant after adjustment, with adjusted odds ratios of 1.60 (95\% CI $0.95-2.68$ ) and 1.02 (95\% CI 0.72-1.44), respectively. There were no statistically significant interactions between principal/secondary diagnosis status and MRA prescription at discharge with 
Table 1 Patient Characteristics by Principal vs Secondary Diagnosis $(N=1500)$

\begin{tabular}{|c|c|c|c|c|}
\hline & Total $N=1500$ & Principal HF Hospitalization $N=407$ & Secondary HF Hospitalization N=1093 & $\mathrm{p}$-value \\
\hline \multicolumn{5}{|l|}{ Demographics } \\
\hline Age, Mean \pm SD & $71.9 \pm 13.6$ & $71.8 \pm 13.6$ & $71.9 \pm 13.6$ & 0.88 \\
\hline Female, n (\%) & $443(29.5 \%)$ & $110(27.0 \%)$ & $333(30.5 \%)$ & 0.19 \\
\hline Black & $227(15.1 \%)$ & $87(21.4 \%)$ & $140(12.8 \%)$ & $<0.0001$ \\
\hline Hispanic & $97(6.5 \%)$ & $30(7.4 \%)$ & $67(6.1 \%)$ & 0.38 \\
\hline \multicolumn{5}{|l|}{ Comorbid conditions } \\
\hline Hypertension & 1151 (76.7\%) & $331(81.3 \%)$ & $820(75.0 \%)$ & 0.01 \\
\hline Atrial fibrillation & $792(52.8 \%)$ & $211(51.8 \%)$ & $581(53.2 \%)$ & 0.65 \\
\hline Diabetes mellitus & $617(41.1 \%)$ & $194(47.7 \%)$ & $423(38.7 \%)$ & 0.002 \\
\hline Chronic kidney disease & $511(34.1 \%)$ & $164(40.3 \%)$ & $347(31.8 \%)$ & 0.002 \\
\hline Malignancy & $325(21.7 \%)$ & $95(23.3 \%)$ & $230(21.4 \%)$ & 0.34 \\
\hline COPD & $244(16.3 \%)$ & $81(19.9 \%)$ & $163(14.9 \%)$ & 0.02 \\
\hline Myocardial infarction & $241(16.1 \%)$ & $41(10.1 \%)$ & $200(18.3 \%)$ & 0.0001 \\
\hline Cerebrovascular disease & $204(13.6 \%)$ & $57(14.0 \%)$ & $147(13.5 \%)$ & 0.78 \\
\hline Peripheral vascular disease & $170(11.3 \%)$ & $32(7.9 \%)$ & $138(12.6 \%)$ & 0.01 \\
\hline Dementia & $141(9.4 \%)$ & $47(11.6 \%)$ & $94(8.6 \%)$ & 0.08 \\
\hline Cirrhosis & $27(1.8 \%)$ & $7(1.7 \%)$ & $20(1.8 \%)$ & 0.89 \\
\hline LVEF \%, Mean \pm SD & $26.4 \pm 7.2$ & $24.4 \pm 7.5$ & $27.2 \pm 7.0$ & $<0.0001$ \\
\hline \multicolumn{5}{|c|}{ Admission Blood Pressure, Labs, \& Home Medications } \\
\hline $\mathrm{SBP}$, Mean $\pm \mathrm{SD}, \mathrm{mm} \mathrm{Hg}$ & $130.7 \pm 23.8$ & $134.3 \pm 25.7$ & $129.4 \pm 22.9$ & 0.001 \\
\hline Sodium, Mean \pm SD, mEq/L & $137.4 \pm 4.4$ & $137.7 \pm 4.4$ & $137.4 \pm 4.5$ & 0.21 \\
\hline Potassium, Mean $\pm \mathrm{SD}, \mathrm{mEq} / \mathrm{L}$ & $4.4 \pm 0.6$ & $4.4 \pm 0.6$ & $4.4 \pm 0.6$ & 0.86 \\
\hline Creatinine, Mean $\pm S D$, mg/dL & $1.2 \pm 0.5$ & $1.3 \pm 0.5$ & $1.2 \pm 0.5$ & 0.11 \\
\hline $\mathrm{eGFR}$, Mean $\pm \mathrm{SD}, \mathrm{ml} / \mathrm{min} / 1.73 \mathrm{~m}^{2}$ & $63.6 \pm 24.9$ & $61.4 \pm 22.0$ & $64.4 \pm 25.9$ & 0.03 \\
\hline ACE-inhibitor or ARB & $882(58.8 \%)$ & $237(58.2 \%)$ & $635(58.1 \%)$ & 0.36 \\
\hline Beta-blocker & $1095(73.0 \%)$ & $299(73.5 \%)$ & $796(72.8 \%)$ & 0.80 \\
\hline Loop diuretic & $864(57.6 \%)$ & $275(67.6 \%)$ & $589(53.9 \%)$ & $<0.0001$ \\
\hline \multicolumn{5}{|l|}{ Discharge Labs \& Medications } \\
\hline Creatinine, Mean $\pm \mathrm{SD}, \mathrm{mg} / \mathrm{dL}$ & $1.2 \pm 0.4$ & $1.2 \pm 0.4$ & $1.1 \pm 0.4$ & $<0.0001$ \\
\hline eGFR, Mean \pm SD, $\mathrm{ml} / \mathrm{min} / 1.73 \mathrm{~m}^{2}$ & $65.4 \pm 24.0$ & $61.4 \pm 22.0$ & $64.4 \pm 25.9$ & $<0.0001$ \\
\hline Potassium, Mean $\pm \mathrm{SD}, \mathrm{mEq} / \mathrm{L}$ & $4.2 \pm 0.4$ & $4.2 \pm 0.4$ & $4.3 \pm 0.4$ & 0.01 \\
\hline ACE-inhibitor or ARB & $975(65.0 \%)$ & $287(70.5 \%)$ & $688(63.0 \%)$ & 0.006 \\
\hline Beta-blocker & $1184(78.9 \%)$ & $323(79.4 \%)$ & $861(78.8 \%)$ & 0.80 \\
\hline Loop diuretic & $1022(68.1 \%)$ & $339(83.3 \%)$ & $683(62.5 \%)$ & $<0.0001$ \\
\hline \multicolumn{5}{|l|}{ Primary Service* } \\
\hline Cardiology & $668(44.5 \%)$ & $284(69.8 \%)$ & $384(35.1 \%)$ & $<0.0001$ \\
\hline Medicine & $411(27.4 \%)$ & 85 (20.9\%) & $326(29.8 \%)$ & 0.0006 \\
\hline Other & $395(26.3 \%)$ & 28 (6.9\%) & 367 (33.6\%) & $<0.0001$ \\
\hline
\end{tabular}

Abbreviations: COPD Chronic Obstructive Pulmonary Disease, LVEF left ventricular ejection fraction, eGFR estimated glomerular filtration rate $\left(\mathrm{ml} / \mathrm{min} / 1.73 \mathrm{~m}^{2}\right), A C E$ angiotensin converting enzyme, ARB Angiotensin Receptor Blocker, SBP systolic blood pressure. *Primary Service totals do not add up to $100 \%$ due to missing data ( $2 \%$ of admissions)

regards to all of the outcomes studied, with $p$-values for interaction ranging from 0.13 to 0.81 (Table 2).

\section{Discussion}

Among hospitalized patients with heart failure with a reduced ejection fraction who met guideline- directed indications for MRA, use was infrequent both before and after hospitalization. We found a small increase in patients prescribed MRA from one out of five patients before hospitalization to one out of four patients after hospitalization. We found that MRA were underutilized due to a combination of ambulatory 


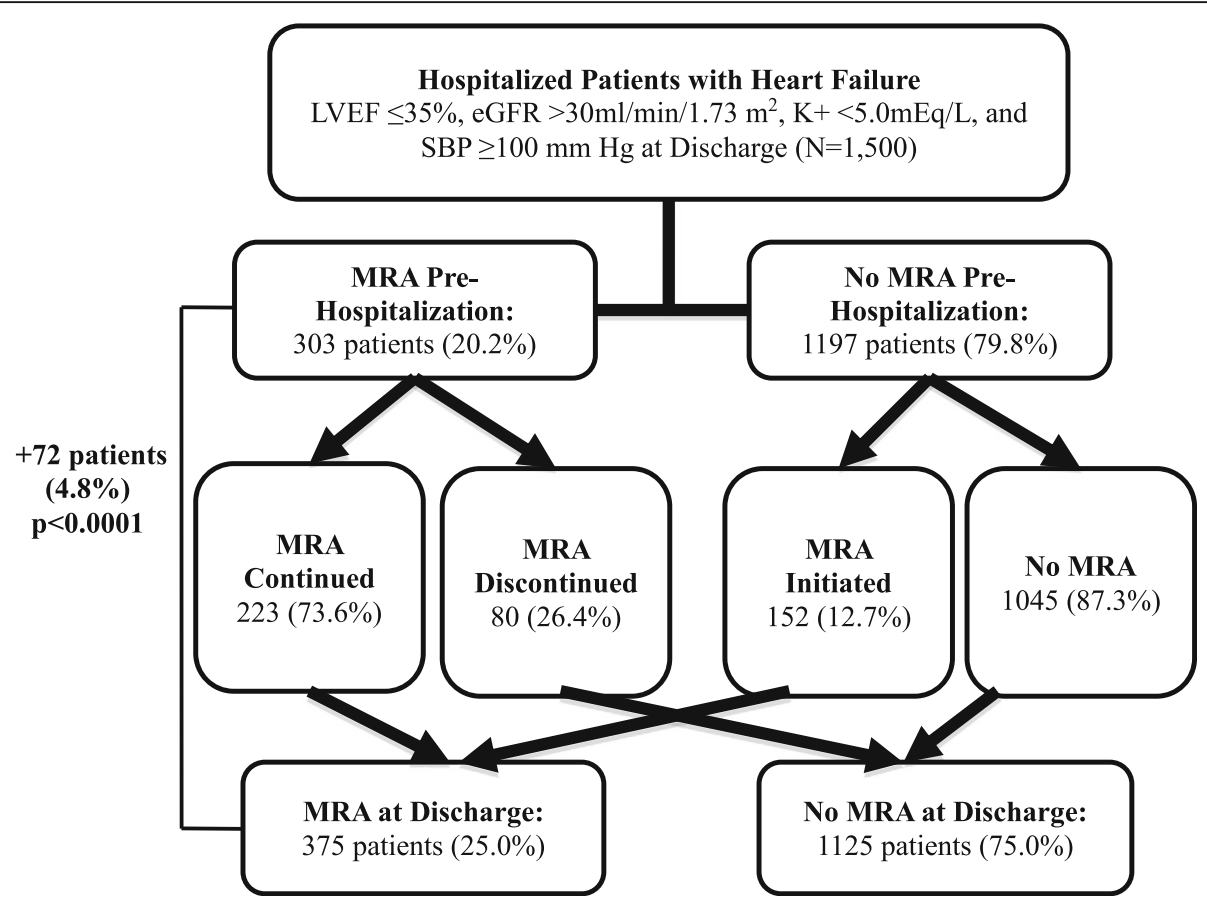

Fig. 1 MRA Prescriptions Before and After Hospitalization $(N=1500)$. Change in MRA prescription before and after hospitalization $(N=1500)$. Overall, there was a net increase from $303(20.2 \%)$ to 375 (25.0\%) patients prescribed MRA at discharge compared to admission ( $p<0.0001)$. Abbreviations: MRA = mineralocorticoid receptor antagonist, $\mathrm{LVEF}=$ left ventricular ejection fraction, eGFR = estimated glomerular filtration rate $\left(\mathrm{ml} / \mathrm{min} / 1.73 \mathrm{~m}^{2}\right), \mathrm{K}+$ =potassium $(\mathrm{mEq} / \mathrm{L}), \mathrm{SBP}=$ systolic blood pressure $(\mathrm{mm} \mathrm{Hg})$

underuse preceding hospitalization (20\%), high discontinuation rates during hospitalization (26\%), and low initiation rates at discharge (13\%). Our findings highlight an opportunity to identify appropriate candidates and initiate MRA throughout the continuum of care.

MRA utilization was particularly low for patients with HFrEF who were hospitalized for other causes: only $21 \%$ of patients with a secondary diagnosis of heart failure compared to $35 \%$ of patients with a principal diagnosis received MRA at discharge. Patients with a secondary diagnosis had lower rates of MRA prescription preceding hospitalization, lower rates of MRA initiation during hospitalization, and similar rates of discontinuation by time of discharge. It may be appropriate to have higher discontinuation rates and lower rates of MRA initiation for patients with diagnoses such as sepsis or gastrointestinal bleeding, but this does not explain lower rates of ambulatory prescription preceding hospitalization or similar rates of discontinuation that we found. Despite this caveat, these findings highlight a missed opportunity to initiate MRA, especially among patients with heart failure

Table 2 Post-Discharge Outcomes by Mineralocorticoid Receptor Antagonist (MRA) Prescription Status ( $N=1463)$

\begin{tabular}{|c|c|c|c|c|c|}
\hline & $\begin{array}{l}\text { MRA Prescribed at Discharge } \\
(N=365)\end{array}$ & $\begin{array}{l}\text { MRA Not Prescribed } \\
\text { at Discharge } \\
(N=1098)\end{array}$ & $\begin{array}{l}\text { Unadjusted Odds Ratio } \\
\text { for MRA Prescription } \\
(\text { ref = no MRA) }(95 \% \text { Cl) }\end{array}$ & $\begin{array}{l}\text { Adjusted Odds Ratio } \\
\text { for MRA Prescription } \\
(\text { ref = no MRA) }(95 \% \text { Cl) }\end{array}$ & $\begin{array}{l}\text { Interaction between } \\
\text { MRA and Principal/ } \\
\text { Secondary Diagnosis, } \\
p \text {-value }\end{array}$ \\
\hline 30-day Readmission & $81(22.2 \%)$ & $237(21.6 \%)$ & $1.04(0.78-1.38)$ & $1.14(0.84-1.57)$ & 0.53 \\
\hline 180-day Readmission & $159(43.6 \%)$ & $509(46.4 \%)$ & $0.89(0.70-1.13)$ & $0.86(0.67-1.11)$ & 0.14 \\
\hline 30-day Mortality & $11(3.0 \%)$ & $27(2.5 \%)$ & $1.23(0.61-2.51)$ & $1.42(0.67-3.03)$ & 0.34 \\
\hline 180-day Mortality & $34(9.3 \%)$ & $112(10.2 \%)$ & $0.90(0.60-1.35)$ & $1.17(0.76-1.79)$ & 0.35 \\
\hline $\begin{array}{l}\text { 30-day Heart Failure } \\
\text { Readmission }\end{array}$ & $27(7.4 \%)$ & $49(4.5 \%)$ & $1.71(1.05-2.78)$ & $1.60(0.95-2.68)$ & 0.13 \\
\hline $\begin{array}{l}\text { 180-day Heart Failure } \\
\text { Readmission }\end{array}$ & 76 (20.8\%) & $170(15.5 \%)$ & $1.44(1.06-1.94)$ & $1.02(0.72-1.44)$ & 0.45 \\
\hline $\begin{array}{l}\text { 30-day Hyperkalemia } \\
\text { Readmission }\end{array}$ & $7(1.9 \%)$ & $13(1.2 \%)$ & $1.63(0.65-4.12)$ & $1.92(0.70-5.24)$ & 0.62 \\
\hline $\begin{array}{l}\text { 180-day Hyperkalemia } \\
\text { Readmission }\end{array}$ & $19(5.2 \%)$ & $52(4.7 \%)$ & $1.10(0.64-1.89)$ & $1.00(0.55-1.84)$ & 0.81 \\
\hline
\end{tabular}


hospitalized for other reasons, which represent over three quarters of hospitalizations of patients with heart failure in the United States [22].

MRA prescription at discharge was not associated with differences in mortality and all-cause readmissions at 30 days and 180 days post-discharge, similar to a recent registrybased propensity-score matched cohort study [23]. In unadjusted analysis there were increased odds of heart failure specific readmission among patients who were versus who were not prescribed MRA at discharge; this difference was no longer significant after adjustment. Overall rates for hyperkalemia readmissions were low with no difference in rates among patients prescribed versus not prescribed MRA at discharge. Additionally, we found no differences in association of MRA use with outcomes for patients with a principal versus secondary diagnosis of heart failure. These findings, which should be considered exploratory analyses, suggest that prescribing MRA at discharge is not associated with adverse short-term outcomes and should be safe to initiate during care transitions.

Overall, our results that MRA are underutilized and frequently discontinued are consistent with prior studies, which predominantly included patients with acute decompensated heart failure [11, 13-15, 24-28]. Similar to our findings, one prior study that included patients with a secondary diagnosis of heart failure found that these patients were less likely to receive guideline-directed therapy including MRA than patients with a principal diagnosis of heart failure [18]. With significantly lower MRA prescription rates and MRA initiation rates among secondary heart failure patients, there is a greater opportunity to improve the quality of care for patients with a secondary diagnosis of HFrEF.

MRA are underused due to a combination of provider and patient-specific factors, primarily due to concerns about the risk of hyperkalemia [28]. Other barriers include knowledge gaps among physicians regarding patient eligibility, uncertainty regarding who should prescribe them during transitions of care, and concerns about polypharmacy, adverse effects, lack of follow-up, and non-adherence $[9,29]$. To mitigate the risk of hyperkalemia, timely followup laboratory testing is critical especially in patients with underlying chronic kidney disease [30-32]. Inpatient MRA initiation increases appropriate laboratory follow-up to $25.2 \%$ from $2.8 \%$ for outpatient MRA initiation [33].

Despite these concerns, MRA prescription at discharge is associated with increased adherence and better outcomes. Patients are six times more likely to fill MRA prescriptions after heart failure hospitalization if they received an MRA prescription at discharge [11]. Likewise, among eligible patients not prescribed an MRA at discharge, only $5-13 \%$ subsequently had MRA initiated as outpatients $[11,27]$. Increased MRA use in appropriate heart failure patients may be associated with decreased heart-failure readmissions $[23,26]$ and lower mortality [28, 34]. In summary, initiation of MRA for appropriate patients during hospitalization may increase the likelihood that patients receive MRA compared to deferring initiation to the outpatient setting, which may in turn improve outcomes.

\section{Limitations}

First, as an observational study, the outcomes portion of our study may be subject to residual confounding and treatment selection bias. Second, by including a large number of patients with a secondary diagnosis of heart failure, we included some patients for whom it may not be appropriate to initiate an MRA at the time of discharge, such as patients admitted with sepsis or gastrointestinal bleeding. Third, we studied patients hospitalized within a single academic hospital system who may not be representative of the general population. Fourth, we did not determine whether patients filled or were adherent to MRA prescriptions provided on discharge, although prior data suggest that most patients prescribed MRA fill them [11]. Fifth, our study may have been underpowered for some 30-day outcomes including mortality and hyperkalemia readmissions, which we included as important safety outcomes. Sixth, our data lacked outpatient potassium results, so it is possible that we missed adverse events that did not require rehospitalization. Seventh, we did not collect data regarding use of device therapy such as implantable cardioverter-defibrillators and cardiac resynchronization therapy. This is important as both ICD and CRT may affect prognosis in patients with HFrEF, particularly those with diabetes, who may have higher burden of arrhythmias and differential responses to device therapy and interaction with MRA [35, 36]. Finally, NYHA class was not available and brain natriuretic peptide was not checked in the many patients, so it is possible that a small number of patients with a secondary diagnosis of heart failure had NYHA Class I symptoms, suggesting MRA therapy may not be strictly indicated for these patients according to current guidelines $[7,8,26]$.

\section{Conclusions}

MRA remain an under-utilized therapy in heart failure, and hospitalization is a missed opportunity to evaluate whether patients' medications are optimized. Most hospitalized HFrEF patients who meet guideline-directed indication for MRA therapy do not receive MRA before or after hospitalization. Even fewer hospitalized heart failure patients have MRA newly initiated at discharge and many have them discontinued. The gap between current care and optimal guideline-directed medical therapy is even greater for patients with a secondary diagnosis of heart failure. Hospitalization appears to be a safe time to initiate MRA in appropriate patients to increase utilization of this evidence-based therapy without increased risks of harm. 


\section{Appendix}

Table 3 Patient characteristics by MRA discharge prescription

Total

$N=1500$

MRA after

Hospitalization

No MRA after

Hospitalization

$n=375$

$n=1125$

Demographics

\begin{tabular}{|c|c|c|c|c|}
\hline Age, Mean \pm SD & $71.9 \pm 13.6$ & $69.7 \pm 13.6$ & $72.6 \pm 13.2$ & 0.0003 \\
\hline Female & 443 (29.5\%) & $108(28.8 \%)$ & 335 (29.8\%) & 0.7193 \\
\hline Black & $227(15.1 \%)$ & $67(17.9 \%)$ & $160(14.2 \%)$ & 0.0881 \\
\hline Hispanic & $97(6.5 \%)$ & 37 (9.9\%) & $60(5.3 \%)$ & 0.0020 \\
\hline \multicolumn{5}{|l|}{ Comorbid conditions } \\
\hline Hypertension & $1151(76.7 \%)$ & $282(75.2 \%)$ & 869 (77.2\%) & 0.4171 \\
\hline Atrial fibrillation & $792(52.8 \%)$ & $202(53.9 \%)$ & $590(52.4 \%)$ & 0.6328 \\
\hline Diabetes mellitus & $617(41.1 \%)$ & $166(44.3 \%)$ & $451(40.1 \%)$ & 0.1545 \\
\hline Chronic kidney disease & $511(34.1 \%)$ & $117(31.2 \%)$ & $394(35.0 \%)$ & 0.1762 \\
\hline Malignancy & 325 (21.7\%) & $65(17.3 \%)$ & $260(23.1 \%)$ & 0.0187 \\
\hline COPD & $244(16.3 \%)$ & $57(15.2 \%)$ & $187(16.6 \%)$ & 0.5181 \\
\hline Myocardial infarction & $241(16.1 \%)$ & $61(16.3 \%)$ & $180(16.0 \%)$ & 0.9031 \\
\hline Cerebrovascular disease & $204(13.6 \%)$ & $39(10.4 \%)$ & $165(14.7 \%)$ & 0.0369 \\
\hline Peripheral vascular disease & $170(11.3 \%)$ & $37(9.9 \%)$ & $133(11.8 \%)$ & 0.3009 \\
\hline Dementia & $141(9.4 \%)$ & $30(8.0 \%)$ & $111(9.9 \%)$ & 0.2834 \\
\hline Cirrhosis & $27(1.8 \%)$ & $4(1.1 \%)$ & $23(2.0 \%)$ & 0.2174 \\
\hline LVEF \%, Mean \pm SD & $26.4 \pm 7.2$ & $23.9 \pm 7.0$ & $27.3 \pm 7.1$ & $<0.0001$ \\
\hline \multicolumn{5}{|l|}{ Admission Blood Pressure, Labs, \& Home Medications } \\
\hline Admission Systolic blood pressure, Mean \pm SD & $130.7 \pm 23.8$ & $128.6 \pm 23.3$ & $131.4 \pm 23.9$ & 0.0475 \\
\hline Sodium, Mean \pm SD & $137.4 \pm 4.4$ & $137.6 \pm 4.1$ & $137.4 \pm 4.6$ & 0.3131 \\
\hline Potassium, Mean \pm SD & $4.4 \pm 0.6$ & $4.4 \pm 0.6$ & $4.4 \pm 0.6$ & 0.7813 \\
\hline Creatinine, Mean \pm SD & $1.2 \pm 0.5$ & $1.2 \pm 0.5$ & $1.2 \pm 0.5$ & 0.6580 \\
\hline eGFR, Mean \pm SD & $63.6 \pm 24.9$ & $64.6 \pm 23.3$ & $63.3 \pm 25.4$ & 0.3398 \\
\hline ACE Inhibitor or ARB & $882(58.8 \%)$ & $248(66.1 \%)$ & $634(56.4 \%)$ & 0.0009 \\
\hline Beta blocker & $1095(73.0 \%)$ & $298(79.5 \%)$ & $797(70.8 \%)$ & 0.0011 \\
\hline Loop diuretic & $864(57.6 \%)$ & $262(69.9 \%)$ & $602(53.5 \%)$ & $<0.0001$ \\
\hline \multicolumn{5}{|l|}{ Discharge Labs \& Home Medications } \\
\hline Creatinine, Mean \pm SD & $1.2 \pm 0.4$ & $1.2 \pm 0.4$ & $1.1 \pm 0.4$ & 0.0817 \\
\hline eGFR, Mean \pm SD & $65.4 \pm 24.0$ & $64.7 \pm 23.6$ & $65.6 \pm 24.1$ & 0.5497 \\
\hline Potassium, Mean \pm SD & $4.2 \pm 0.4$ & $4.2 \pm 0.4$ & $4.2 \pm 0.4$ & 0.9968 \\
\hline ACE Inhibitor or ARB & 975 (65.0\%) & $279(74.4 \%)$ & $696(61.9 \%)$ & $<0.0001$ \\
\hline Beta blocker & 1184 (78.9\%) & $336(89.6 \%)$ & $848(75.4 \%)$ & $<0.0001$ \\
\hline Loop diuretic & $1022(68.1 \%)$ & $315(84.0 \%)$ & 707 (62.8\%) & $<0.0001$ \\
\hline \multicolumn{5}{|l|}{ Primary Service* } \\
\hline Cardiology & 668 (44.5\%) & $203(54.1 \%)$ & 465 (41.3\%) & $<0.0001$ \\
\hline Medicine & 411 (27.4\%) & $82(21.9 \%)$ & 329 (29.2\%) & 0.006 \\
\hline Other & 395 (26.3\%) & $86(22.9 \%)$ & 309 (27.5\%) & 0.08 \\
\hline
\end{tabular}

Abbreviations: SD Standard Deviation, COPD Chronic Obstructive Pulmonary Disease, ACE angiotensin converting enzyme, ARB Angiotensin Receptor Blocker, eGFR estimated glomerular filtration rate $\left(\mathrm{ml} / \mathrm{min} / 1.73 \mathrm{~m}^{2}\right)$, LVEF left ventricular ejection fraction. *Primary Service totals do not add up to $100 \%$ due to missing data ( $2 \%$ of admissions). 


\section{Abbreviations}

ACE: Angiotensin converting enzyme; ARB: Angiotensin receptor blocker; Cl: Confidence interval; eGFR: Estimated glomerular filtration rate; GEE: Generalized estimating equations; HFrEF: Heart failure with a reduced ejection fraction; LVEF: Left ventricular ejection fraction; MRA: Mineralocorticoid receptor antagonist; NYHA: New York Heart Association; OR: Odds ratio; SBP: Systolic blood pressure

\section{Acknowledgements}

Not applicable.

\section{Availability of data data and materials}

The datasets generated and/or analyzed during the current study are not publicly available but may be made available from the corresponding author on reasonable request. Permission to use these data was granted by NYU Langone Health.

\section{Authors' contributions}

MSD and SB designed the study with critical input from SDK, SB designed the data linkage. MSD validated the data. HP and MSD conducted the data analysis. MSD wrote the first draft of the manuscript. SDK and SB provided critical input on early drafts of the manuscript. All authors edited and approved the final manuscript.

\section{Funding}

Dr. Blecker is supported by AHRQ K08 HS23683. The funding source had no role in study design, data collection, analysis or interpretation, writing the manuscript, or decision to publish the findings.

\section{Ethics approval and consent to participate}

This study was approved by the New York University School of Medicine Institutional Review Board, and a waiver of consent was granted due to the retrospective nature of the study.

\section{Consent for publication}

\section{Not applicable.}

\section{Competing interests}

The authors declare that they have no competing interests to declare.

\section{Author details}

'Department of Medicine, Division of Cardiology, University of California, San Francisco, Box 0124, C/O Salina Gu, San Francisco, CA 94143, USA. 2Department of Medicine, New York University School of Medicine, 227 East 30th Street, New York, NY 10016, USA. ${ }^{3}$ Department of Population Health, New York University School of Medicine, 227 East 30th Street, New York, NY 10016, USA

Received: 5 April 2019 Accepted: 31 July 2019

Published online: 09 August 2019

\section{References}

1. Heidenreich PA, Albert NM, Allen LA, Bluemke DA, Butler J, Fonarow GC, et al. Forecasting the impact of heart failure in the United States: a policy statement from the American Heart Association. Circ Heart Fail. 2013;6(3):606-19.

2. Pitt B, Zannad F, Remme WJ, Cody R, Castaigne A, Perez A, et al. The effect of spironolactone on morbidity and mortality in patients with severe heart failure. Randomized Aldactone Evaluation Study Investigators. N Engl J Med. 1999:341(10):709-17.

3. Pitt B, White H, Nicolau J, Martinez F, Gheorghiade M, Aschermann M, et al. Eplerenone reduces mortality 30 days after randomization following acute myocardial infarction in patients with left ventricular systolic dysfunction and heart failure. J Am Coll Cardiol. 2005:46(3):425-31.

4. Zannad F, McMurray JJ, Krum H, van Veldhuisen DJ, Swedberg K, Shi H, et al. Eplerenone in patients with systolic heart failure and mild symptoms. N Engl J Med. 2011;364(1):11-21.

5. Pitt B, Remme W, Zannad F, Neaton J, Martinez F, Roniker B, et al. Eplerenone, a selective aldosterone blocker, in patients with left ventricular dysfunction after myocardial infarction. N Engl J Med. 2003;348(14):1309-21.

6. De Vecchis $\mathrm{R}$, Cantatrione C, Mazzei D, Barone A, Maurea N. The Impact Exerted on Clinical Outcomes of Patients With Chronic Heart Failure by
Aldosterone Receptor Antagonists: A Meta-Analysis of Randomized Controlled Trials. J Clin Med Res. 2017:9(2):130-42.

7. Yancy CW, Jessup M, Bozkurt B, Butler J, Casey DE. 2013 ACCF/AHA Guideline for the Management of Heart Failure: A Report of the American College of Cardiology Foundation/American Heart Association Task Force on Practice Guidelines. Circulation. 2013;128:e240-327.

8. Yancy CW, Jessup M, Bozkurt B, Butler J, Casey DE Jr, Colvin MM, et al. 2017 ACC/AHA/HFSA Focused Update of the 2013 ACCF/AHA Guideline for the Management of Heart Failure: A Report of the American College of Cardiology/American Heart Association Task Force on Clinical Practice Guidelines and the Heart Failure Society of America. Circulation. 2017;136:e137-61.

9. Hirt MN, Muttardi A, Helms TM, van den Bussche H, Eschenhagen T. General practitioners' adherence to chronic heart failure guidelines regarding medication: the GP-HF study. Clin Res Cardiol. 2016;105(5):441-50.

10. Margolis J, Gerber RA, Roberts C, Gheorghiade M. Adherence to aldosteroneblocking agents in patients with heart failure. Am J Ther. 2010;17(5):446-54

11. Curtis LH, Mi X, Qualls LG, Check DK, Hammill BG, Hammill SC, et al. Transitional adherence and persistence in the use of aldosterone antagonist therapy in patients with heart failure. Am Heart J. 2013;165(6):979-86 e1.

12. Bress AP, King JB, Brixner D, Kielhorn A, Patel HK, Maya J, et al. Pharmacotherapy Treatment Patterns, Outcomes, and Health Resource Utilization Among Patients with Heart Failure with Reduced Ejection Fraction at a U.S. Academic Medical Center. Pharmacotherapy. 2016;36(2):174-86.

13. Albert NM, Yancy CW, Liang L, Zhao X, Hernandez AF, Peterson ED, et al. Use of aldosterone antagonists in heart failure. JAMA. 2009:302(15):1658-65.

14. Chamsi-Pasha MA, Dupont M, Al Jaroudi WA, Tang WH. Utilization pattern of mineralocorticoid receptor antagonists in contemporary patients hospitalized with acute decompensated heart failure: a single-center experience. J Card Fail. 2014;20(4):229-35.

15. Krantz MJ, Ambardekar AV, Kaltenbach L, Hernandez AF, Heidenreich PA, Fonarow GC, et al. Patterns and predictors of evidence-based medication continuation among hospitalized heart failure patients (from Get With the Guidelines-Heart Failure). Am J Cardiol. 2011;107(12):1818-23.

16. Dev S, Lacy ME, Masoudi FA, Wu WC. Temporal Trends and Hospital Variation in Mineralocorticoid Receptor Antagonist Use in Veterans Discharged With Heart Failure. J Am Heart Assoc. 2015;4(12).

17. Deschaseaux C, McSharry M, Hudson E, Agrawal R, Turner SJ. Treatment Initiation Patterns, Modifications, and Medication Adherence Among Newly Diagnosed Heart Failure Patients: A Retrospective Claims Database Analysis. J Manag Care Spec Pharm. 2016;22(5):561-71.

18. Blecker S, Agarwal SK, Chang PP, Rosamond WD, Casey DE, KucharskaNewton A, et al. Quality of care for heart failure patients hospitalized for any cause. J Am Coll Cardiol. 2014;63(2):123-30.

19. McCormick N, Lacaille D, Bhole V, Avina-Zubieta JA. Validity of Heart Failure Diagnoses in Administrative Databases: A Systematic Review and MetaAnalysis. PLoS One. 2014;9(8):e104519.

20. Durstenfeld MS, Ogedegbe O, Katz SD, Park H, Blecker S. Racial and Ethnic Differences in Heart Failure Readmissions and Mortality in a Large Municipal Healthcare System. JACC Heart Fail. 2016;4(11):885-93.

21. Levey AS, Stevens LA, Schmid CH, Zhang YL, Castro AF 3rd, Feldman HI, et al. A new equation to estimate glomerular filtration rate. Ann Intern Med. 2009:150(9):604-12.

22. Blecker S, Paul M, Taksler G, Ogedegbe G, Katz S. Heart failure-associated hospitalizations in the United States. J Am Coll Cardiol. 2013;61(12):1259-67.

23. Yaku H, Kato T, Morimoto T, Inuzuka Y, Tamaki Y, Ozasa N, et al. Association of Mineralocorticoid Receptor Antagonist Use With All-Cause Mortality and Hospital Readmission in Older Adults With Acute Decompensated Heart Failure. JAMA Netw Open. 2019;2(6):e195892.

24. Ferreira JP, Rossignol P, Machu JL, Sharma A, Girerd N, Anker SD, et al. Mineralocorticoid receptor antagonist pattern of use in heart failure with reduced ejection fraction: findings from BIOSTAT-CHF. Eur J Heart Fail. 2017;19(10):1284-93.

25. Fonarow GC, Albert NM, Curtis AB, Gheorghiade M, Liu Y, Mehra MR, et al. Incremental Reduction in Risk of Death Associated With Use of GuidelineRecommended Therapies in Patients With Heart Failure: A Nested CaseControl Analysis of IMPROVE HF. J Am Heart Assoc. 2012;1 (1):16-26.

26. Hernandez AF, Mi X, Hammill BG, Hammill SC, Heidenreich PA, Masoudi FA, et al. Associations between aldosterone antagonist therapy and risks of mortality and readmission among patients with heart failure and reduced ejection fraction. JAMA. 2012;308(20):2097-107. 
27. Wang TY, Vora AN, Peng SA, Fonarow GC, Das S, de Lemos JA, et al. Effectiveness and Safety of Aldosterone Antagonist Therapy Use Among Older Patients With Reduced Ejection Fraction After Acute Myocardial Infarction. J Am Heart Assoc. 2016;5(1).

28. Hernandez AF, Hammill BG, Peterson ED, Yancy CW, Schulman KA, Curtis $\mathrm{LH}$, et al. Relationships between emerging measures of heart failure processes of care and clinical outcomes. Am Heart J. 2010;159(3):406-13.

29. Dev S, Hoffman TK, Kavalieratos D, Heidenreich P, Wu WC, Schwenke DC, et al. Barriers to Adoption of Mineralocorticoid Receptor Antagonists in Patients With Heart Failure: A Mixed-Methods Study. J Am Heart Assoc. 2016:5(3):e002493.

30. Pitt B, Rossignol P. The safety of mineralocorticoid receptor antagonists (MRAs) in patients with heart failure. Expert Opin Drug Saf. 2016;15(5):659-65.

31. Vukadinovic D, Lavall D, Vukadinovic AN, Pitt B, Wagenpfeil S, Bohm M. True rate of mineralocorticoid receptor antagonists-related hyperkalemia in placebo-controlled trials: A meta-analysis. Am Heart J. 2017;188:99-108.

32. Shah KB, Rao K, Sawyer R, Gottlieb SS. The adequacy of laboratory monitoring in patients treated with spironolactone for congestive heart failure. J Am Coll Cardiol. 2005;46(5):845-9.

33. Cooper LB, Hammill BG, Peterson ED, Pitt B, Maciejewski ML, Curtis LH, et al. Characterization of Mineralocorticoid Receptor Antagonist Therapy Initiation in High-Risk Patients With Heart Failure. Circ Cardiovasc Qual Outcomes. 2017;10(1)

34. Berbenetz NM, Mrkobrada M. Mineralocorticoid receptor antagonists for heart failure: systematic review and meta-analysis. BMC Cardiovasc Disord. 2016;16(1):246.

35. Sardu C, Marfella R, Santulli G. Impact of Diabetes Mellitus on the Clinical Response to Cardiac Resynchronization Therapy in Elderly People. J Cardiovasc Transl Res. 2014;7(3):362-8.

36. Sardu C, Santamaria M, Funaro S, Sacra C, Barbieri M, Paolisso P, et al. Cardiac electrophysiological alterations and clinical response in cardiac resynchronization therapy with a defibrillator treated patients affected by metabolic syndrome. Medicine (Baltimore). 2017;96(14):e6558.

\section{Publisher's Note}

Springer Nature remains neutral with regard to jurisdictional claims in published maps and institutional affiliations.

Ready to submit your research? Choose BMC and benefit from:

- fast, convenient online submission

- thorough peer review by experienced researchers in your field

- rapid publication on acceptance

- support for research data, including large and complex data types

- gold Open Access which fosters wider collaboration and increased citations

- maximum visibility for your research: over $100 \mathrm{M}$ website views per year

At $\mathrm{BMC}$, research is always in progress.

Learn more biomedcentral.com/submissions 